\title{
ANALISIS KEPUASAN PENGUNJUNG EKOWISATA KABUPATEN MALANG
}

\author{
Arfida Boedirachminarni \\ Muhammad Sri Wahyudi Suliswanto \\ Jurusan Ilmu Ekonomi dan Pembangunan \\ Fakultas Ekonomi dan Bisnis Universitas Muhammadiyah Malang \\ E-mail: al.ayudie@gmail.com
}

\begin{abstract}
This study aims to identify the factors that affect the satisfaction of ecotourism visitors Malang regency. The analytical tool used is to identify the factors that influence ecotourism performance using multiple regression analysis. The results of the analysis can be obtained the following conclusions: First, the influence of entertainment and supporting facilities are not significant indicate that the two variables are not the main determinant of visitor satisfaction as a representation of ecotourism performance. However, services and natural conditions are significantly more influential on ecotourism performance in Malang Regency. Secondly, the success of ecotourism is determined by management management as the result of analysis shows that service is the dominant variable in influencing visitor's satisfaction, so it needs synergy from all parties including government policy.
\end{abstract}

Keywords: Tourism Potential, Ecotourism Development, and Malang

\begin{abstract}
Abstrak
Penelitian ini bertujuan untuk mengidentifikasi faktor-faktor yang mempengaruhi kepuasan pengunjung ekowisata Kabupaten Malang. Alat analisis yang digunakan adalah untuk identifikasi faktor-faktor yang mempengaruhi kinerja ekowisata menggunakan analisis regresi berganda. Hasil analisis dapat diperoleh kesimpulan sebagai berikut: pertama, Pengaruh hiburan dan sarana pendukung yang tidak signifikan menunjukkan bahwa kedua variabel tersebut bukanlah menjadi penentu utama kepuasan pengunjung sebagai representasi dari kinerja ekowisata. Akan tetapi, pelayanan dan kondisi alam yang lebih berpengaruh secara signifikan terhadap kinerja ekowisata di Kabupaten Malang. Kedua, Keberhasilan ekowisata sangat ditentukan dari manajemen pengelolaan sebagaimana hasil analisis yang menunjukkan pelayanan merupakan variabel yang dominan dalam mempengaruhi kepuasan pengunjung, sehingga hal ini membutuhkan sinergi dari semua pihak termasuk juga kebijakan pemerintah.
\end{abstract}

Kata Kunci: Potensi Wisata, Pengembangan Ekowisata, dan Malang

\section{PENDAHULUAN}

\begin{tabular}{lll}
\multicolumn{2}{c}{ Pemberlakuan otonomi } & pembangunan ekonomi yang kuat dan \\
daerah pada tahun 2001 menuntut & berkelanjutan. Salah satu upaya \\
setiap pemerintah daerah untuk & pemanfaatan sumber daya lokal yang \\
mengoptimalkan setiap sumberdaya & optimal adalah dengan \\
yang dimiliki untuk mencapai & mengembangkan pariwisata dengan
\end{tabular}


konsep Ekowisata. Dalam konteks ini wisata yang dilakukkan memiliki bagian yang tidak terpisahkan dengan upaya-upaya konservasi, pemberdayaan ekonomi lokal dan mendorong respek yang lebih tinggi terhadap perbedaan kultur atau budaya. Hal inilah yang mendasari perbedaan antara konsep ekowisata dengan model wisata konvensional yang telah ada sebelumnya.

Secara sederhana, konsep ekowisata menghubungkan antara perjalanan wisata alam yang memiliki visi dan misi konservasi dan kecintaan lingkungan. Hal ini dapat terjadi karena keuntungan finansial yang didapat dari biaya perjalanan wisata digunakan juga untuk kebutuhan konservasi alam serta perbaikan kesejahteraan penduduk lokal. Di sisi lain, konsep Ekowisata juga diarahkan untuk mempertahankan kebudayaan lokal serta tidak melanggar hak asasi manusia (HAM) dan pergerakan demografi.

Salah satu daerah yang memiliki keunggulan alam yang potensial dengan didukung oleh berbagai prasyarat untuk mengembangkan keparawisataannya khususnya dalam sektor ekowisata adalah Kabupaten Malang, sehingga Malang mendapat julukan sebagai Paris van East Java dikarenakan kondisi alamnya yang indah, iklimnya yang sejuk dan kotanya yang bersih, bagaikan kota "Paris"nya Jawa Timur. Namun demikian, dengan berbagai potensi ekowisata yang besar tersebut, pengembangan ekowisata masih terkendala berbagai hal diantaranya adalah sarana dan prasarana infrastruktur yang belum memadai, partisipasi masayarakat lokal masih minim, kurangnya promosi, dan dukungan pemerintah yang belum bersinergi secara optimal.

Hal ini terlihat dari hasil penelitian Nuraini dan Suliswanto (2014) bahwa daerah seperti Kecamatan Sumbermanjing Wetan, Bantur, Gedangan, Tumpang, Jabung, Poncokusumo, dan Wajak tergolong pada pola pertumbuhan wilayah "Relatif Tertinggal". daerah yang termasuk dalam kategori ini adalah daerah yang secara ekonomis sangat tertinggal, baik dari segi pertumbuhan ekonomi maupun pendapatan per kapita. Dengan kata lain, daerah 
dalam kategori ini adalah daerah yang paling buruk keadaannya dibandingkan daerah lain di Kabupaten Malang. Padahal daerahdaerah tersebut memiliki potensi alam yang menarik tetapi belum mampu memberikan kontribusi yang besar bagi perekonomian.

Hasil

penelitian

Boedirachminarni dan Suliswanto (2015) menunjukkan bahwa bahwa potensi bisnis wisata dapat dipetakan menjadi 5 (lima) bagian yaitu Malang Barat, Timur, Selatan A, Selatan B, dan Utara. Masing-masing wilayah memiliki karakteristik wisata sendiri. Malang Barat dan Timur memiliki karakteristik wisata wilayah pegunungan, Malang selatan memiliki karakteristik wisata wilayah kelautan, dan Malang Utara memiliki karakteristik wisata peninggalan sejarah. Potensi yang dimiliki Kabupaten Malang tersebut masih belum dikelola secara optimal yang dibuktikan masih banyaknya kelemahan dalam pengelolaan wisata di Kabupaten Malang. Berdasarkan uraian diatas, maka diperlukan analisis faktor-faktor apa yang mempengaruhi kepuasan pengunjung ekowisata di Kabupaten Malang.
Secara konseptual ekowisata dapat didefinisikan sebagai suatu konsep pengembangan pariwisata berkelanjutan yang bertujuan untuk mendukung upaya-upaya pelestarian lingkungan (alam dan budaya) dan meningkatkan partisipasi masyarakat dalam pengelolaan, sehingga memberikan manfaat ekonomi kepada masyarakat setempat. Sementara ditinjau dari segi pengelolaanya, ekowisata dapat didifinisikan sebagai penyelenggaraan kegiatan wisata yang bertanggung jawab di tempattempat alami dan atau daerah-daerah yang dibuat berdasarkan kaidah alam dan secara ekonomi berkelanjutan yang mendukung upaya-upaya pelestarian lingkungan (alam dan budaya) dan meningkatnkan kesejahtraan masyarakat setempat.

Damanik dan Weber (2006) menyatakan bahwa ekowisata sangat memperhatikan prinsip-prinsip yang mengedepankan kelesatrian lingkungan dan keterjagaan lingkungan serta sangat menghormati nilai-nilai budaya setempat. Hal ini mengindikasikan bahwa masyarakat terlibat dan berpartisipasi aktif dalam menjaga keberlanjutan dan 
keberlangsungan kehidupan alam. Sehingga dapat dikatakan bahwa ekowisata tidak hanya merupakan wisata edukasi lingkungan namun juga wisata budaya masyarakat disekitarnya.

\section{METODE PENELITIAN}

Metode yang digunakan dalam pengumpulan informasi dan data yang digunakan dalam penelitian ini meliputi:

1. Untuk memperoleh data sekunder teknik yang digunakan peneliti adalah teknik dokumentasi, dengan cara mengutip atau menyalin dokumen-dokumen yang relevan untuk digunakan sebagai data dalam penelitian ini.

2. Observasi (pengamatan)

Teknik observasi ini digunakan peneliti dalam mengadakan pengamatan terhadap kondisi alam. Selain itu peneliti mengadakan pengamatan dan survei lapang secara langsung terhadap obyek yang diamati, mendengar serta mencatat hasil temuan lapang.

Adapun alat analisis yang digunakan adalah: pertama, Analisa deskriptif, yaitu serangkaian prosedur yang digunakan sebagai upaya pemecahan masalah yang diselidiki dengan menggambarkan/melukiskan keadaan subjek/objek yang akan diteliti (seseorang, masyarakat, dan lain-lain) pada saat sekarang berdasarkan fakta-fakta yang tampak atau sebagaimana adanya.

Kedua, Analisis Regresi. Penelitian ini menggunakan metode analisa regresi linier berganda menurut Gujarati (1978:71) yang dapat diformulasikan ke dalam suatu persamaan berikut:

$\mathrm{Y}=\beta_{0}+\beta_{1} X_{1}+\beta_{2} X_{2}+\beta_{3} X_{3}+\beta_{4} X_{4}+e i$

Dimana:

$\mathrm{Y}=$ Kinerja Ekowisata (Penilaian Pengunjung)

$\mathrm{X}_{1}=$ Fasilitas Pelayanan

$\mathrm{X}_{2}=$ Fasilitas Hiburan

$\mathrm{X}_{3}=$ Sarana Pendukung

$\mathrm{X}_{4}=$ Kondisi Alam

$\beta_{0}=$ Konstanta

ei $=$ Kesalahan peganggu

\section{PEMBAHASAN}

Kinerja ekowisata dalam penelitian ini dapat dilihat dari kepuasan pengunjung, apabila pengunjung semakin puas, maka kinerja ekowisata sangat bagus. Berdasarkan hasil survey kepada pengunjung ekowisata di Kabupaten 
Malang, dapat diketahui bahwa mayoritas pengunjung merasakan cukup puas dengan tempat wisata (ekowisata) di Kabupaten Malang yaitu sebesar 55\%. Selanjutnya, 30\% pengunjung merasakan puas, 9\% sangat puas, dan $6 \%$ tidak puas. Dengan demikian, pemerintah dan pengelola perlu meningkatkan pengelolaannya terhadap ekowisata di Kabupaten Malang agar tingkat kepuasan pengunjung dapat meningkat. Berikut ini akan dibahas pandangan-pandangan pengunjung terhadap kondisi-kondisi faktor yang mempengaruhi kinerja ekowisata.

Pertama, Pelayanan merupakan faktor yang penting terhadap kepuasan pengunjung, pelayanan yang baik akan dapat meningkatkan kepuasan pengunjung. Hasil kuisioner menunjukkan bahwa mayoritas pengunjung merasakan cukup puas dengan pelayanan tempat wisata (ekowisata) di Kabupaten Malang yaitu sebesar $61 \%$. Selanjutnya, $21 \%$ pengunjung merasakan puas, $15 \%$ tidak puas, dan $3 \%$ sangat puas. Besarnya persentase ketidakpuasan sebesar $15 \%$ harus menjadikan perhatian khusus bagi pemerintah dan pengelola agar tingkat ketidakpuasan dapat menurun.

Kedua, Fasilitas hiburan merupakan faktor pendukung yang penting terhadap kepuasan pengunjung, semakin banyaknya pilihan hiburan di lokasi wisata tentu akan dapat meningkatkan kepuasan pengunjung. Mayoritas pengunjung merasakan cukup puas dengan fasilitas hiburan tempat wisata (ekowisata) di Kabupaten Malang yaitu sebesar $61 \%$. Selanjutnya, 24\% pengunjung merasakan tidak puas, $12 \%$ puas, dan $3 \%$ sangat puas. Besarnya persentase ketidakpuasan terhadap fasilitas hiburan sebesar 24\% harus menjadikan perhatian khusus bagi pemerintah dan pengelola agar tingkat ketidakpuasan dapat menurun.

Ketiga, Aksesbilitas merupakan faktor yang penting terhadap kepuasan pengunjung, semakin mudahnya wisatawan menuju lokasi wisata tentu akan dapat meningkatkan kepuasan pengunjung dan dapat memperbanyak pengunjung yang datang. Mayoritas pengunjung merasakan cukup puas dengan aksesbilitas tempat wisata (ekowisata) di Kabupaten Malang 
yaitu sebesar 58\%. Selanjutnya, 27\% pengunjung merasakan tidak puas, $15 \%$ puas. Besarnya persentase ketidakpuasan terhadap aksesbilitas sebesar $27 \%$ harus menjadikan perhatian khusus bagi pemerintah dan pengelola agar tingkat ketidakpuasan dapat menurun dan dapat memperbanyak pengunjung.

Keempat, Sarana pendukung juga merupakan faktor yang penting terhadap kepuasan pengunjung, semakin banyaknya sarana pendukung di lokasi wisata tentu akan dapat meningkatkan kepuasan pengunjung dan dapat memperbanyak pengunjung yang datang. Mayoritas pengunjung merasakan cukup puas dengan sarana pendukung tempat wisata (ekowisata) di Kabupaten Malang yaitu sebesar $67 \%$. Selanjutnya, $18 \%$ pengunjung merasakan tidak puas, $15 \%$ puas. Besarnya persentase ketidakpuasan terhadap sarana pendukung sebesar $18 \%$ harus menjadikan perhatian khusus bagi pemerintah dan pengelola agar tingkat ketidakpuasan dapat menurun dan dapat memperbanyak pengunjung.

Kelima, Kondisi Alam juga merupakan faktor yang utama terhadap kepuasan pengunjung, semakin bagusnya kondisi alam di lokasi wisata tentu akan dapat meningkatkan kepuasan pengunjung dan dapat memperbanyak pengunjung yang datang. Mayoritas pengunjung merasakan puas dengan kondisi alam tempat wisata (ekowisata) di Kabupaten Malang yaitu sebesar $52 \%$. Selanjutnya, 27\% pengunjung merasakan sangat puas, $18 \%$ cukup puas, dan $3 \%$ tidak puas. Besarnya persentase kepuasan terhadap sarana pendukung sebesar 97\% menunjukkan bahwa kondisi alam di lokasi wisata sangatlah bagus, hal ini menjadi daya tarik utama dalam konsep ekowisata.

Besarnya pengaruh pelayanan $\left(\mathrm{X}_{1}\right)$, hiburan $\left(\mathrm{X}_{2}\right)$, sarana pendukung $\left(\mathrm{X}_{3}\right)$ dan kondisi alam $\left(\mathrm{X}_{4}\right)$ terhadap kinerja ekowisata (Y) Kabupaten Malang dilakukan analisis regresi. Adapun model hasil analisis dapat diinterpretasikan sebagai berikut :

$\mathrm{Y}=0,329+0,459 \mathrm{X}_{1}+0,103 \mathrm{X}_{2}+$ $0,140 X_{3}+0,234 X_{4}$

Nilai $\quad \beta_{0} \quad$ menunjukkan konstanta sebesar 0,329 berarti kinerja ekowisata (Y) sebesar 0,329\% pada saat pelayanan $\left(\mathrm{X}_{1}\right)$, hiburan $\left(\mathrm{X}_{2}\right)$, sarana pendukung $\left(\mathrm{X}_{3}\right)$, dan 
kondisi alam $\left(\mathrm{X}_{4}\right)$ sama dengan atau dianggap nol (konstan).

Nilai $\beta_{1}$ merupakan koefisien regresi variabel pelayanan $\left(\mathrm{X}_{1}\right)$ sebesar 0,459 berarti ada pengaruh positif antara pelayanan terhadap kinerja ekowisata sebesar 0,459\%. Apabila pelayanan $\left(\mathrm{X}_{1}\right)$ naik sebesar $1 \%$ maka kinerja ekowisata (Y) juga akan mengalami kenaikan sebesar 0,459\%. Sebaliknya apabila pelayanan $\left(\mathrm{X}_{1}\right)$ turun sebesar $1 \%$ maka kinerja ekowisata (Y) juga akan turun sebesar $0,459 \%$.

Nilai $\beta_{2}$ merupakan koefisien regresi variabel hiburan $\left(\mathrm{X}_{2}\right)$ sebesar 0,103 berarti ada pengaruh positif antara hiburan terhadap kinerja ekowisata sebesar 0,103\%. Apabila hiburan $\left(\mathrm{X}_{2}\right)$ naik sebesar $1 \%$ maka kinerja ekowista (Y) juga akan mengalami kenaikan sebesar $0,103 \%$. Sebaliknya apabila hiburan $\left(\mathrm{X}_{2}\right)$ turun sebesar $1 \%$ maka kinerja ekowisata (Y) juga akan turun sebesar $0,103 \%$.

Nilai $\beta_{3}$ merupakan koefisien regresi variabel sarana pendukung $\left(\mathrm{X}_{3}\right)$ sebesar 0,140 berarti ada pengaruh positif antara sarana pendukung terhadap kinerja ekowisata sebesar $0,140 \%$. Apabila sarana pendukung $\left(\mathrm{X}_{3}\right)$ naik sebesar $1 \%$ maka kinerja ekowisata (Y) juga akan mengalami kenaikan sebesar $0,140 \%$. Sebaliknya apabila sarana pendukung $\left(\mathrm{X}_{3}\right)$ turun sebesar $1 \%$ maka kinerja ekowisata (Y) juga akan turun sebesar $0,140 \%$.

Sedangkan nilai $\beta_{4}$ merupakan koefisien regresi variabel kondisi alam $\left(\mathrm{X}_{4}\right)$ sebesar 0,234 berarti ada pengaruh positif antara kondisi alam terhadap kinerja ekowisata sebesar $0,234 \%$. Apabila kondisi alam $\left(\mathrm{X}_{4}\right)$ naik sebesar $1 \%$ maka kinerja ekowisata (Y) juga akan mengalami kenaikan sebesar $0,234 \%$. Sebaliknya apabila kondisi alam turun sebesar $1 \%$ maka kinerja ekowisata (Y) juga akan turun sebesar $0,234 \%$.

Berdasarkan hasil regresi tersebut dapat disimpulkan bahwa pelayanan $\left(\mathrm{X}_{1}\right)$, hiburan $\left(\mathrm{X}_{2}\right)$, sarana pendukung $\left(\mathrm{X}_{3}\right)$ dan kondisi alam $\left(\mathrm{X}_{4}\right)$ berpengaruh positif terhadap kinerja ekowisata (Y) di Kabupaten Malang.

\section{Uji F test / Serempak}

Pengujian $\mathrm{F}$ atau pengujian model digunakan untuk mengetahui apakah hasil dari analisis signifikan atau tidak, dengan kata lain model 
yang diduga tepat/sesuai atau tidak. Jika hasilnya signifikan, maka $\mathrm{H}_{0}$ ditolak dan $\mathrm{H}_{1}$ diterima. Sedangkan jika hasilnya tidak signifikan, maka $\mathrm{H}_{0}$ diterima dan $\mathrm{H}_{1}$ ditolak.

Berdasarkan Rumus uji F adalah sebagai berikut:

$$
\mathrm{F} \text { test }=\frac{R^{2} /(k-1)}{\left(1-R^{2}\right) /(n-k-1)},
$$

nilai $F$ hitung sebesar 4,744 Sedangkan F tabel $(\alpha=0.05 ; \mathrm{db}$ regresi $=4: \mathrm{db}$ residual $=28)$ adalah sebesar 2,71. Karena F hitung > F tabel yaitu 4,744 > 2,71 maka analisis regresi adalah signifikan. Pengaruh pelayanan $\left(\mathrm{X}_{1}\right)$, hiburan $\left(\mathrm{X}_{2}\right)$, sarana pendukung $\left(\mathrm{X}_{3}\right)$ dan kondisi alam $\left(\mathrm{X}_{4}\right)$ terhadap kinerja ekowisata $(\mathrm{Y})$ adalah besar. Hal ini berarti $\mathrm{H} 1$ diterima sehingga dapat disimpulkan bahwa kinerja ekowisata dapat dipengaruhi secara signifikan oleh pelayanan, hiburan, sarana pendukung dan kondisi alam.

\section{Uji t test / Parsial}

Uji $\mathrm{t}$ test digunakan untuk mengetahui apakah masing-masing variabel bebas secara parsial mempunyai pengaruh yang signifikan terhadap variabel terikat. Dapat juga dikatakan jika t hitung $>\mathrm{t}$ tabel atau $\mathrm{t}$ hitung < - $\mathrm{t}$ tabel maka hasilnya signifikan dan berarti $\mathrm{H}_{0}$ ditolak dan $\mathrm{H}_{1}$ diterima. Sedangkan jika thitung $<\mathrm{t}$ tabel atau -t hitung $>-\mathrm{t}$ tabel maka hasilnya tidak signifikan dan berarti $\mathrm{H}_{0}$ diterima dan $\mathrm{H}_{1}$.

- $\mathrm{t}$ test antara pelayanan $\left(\mathrm{X}_{1}\right)$ dengan kinerja ekowisata (Y) menunjukkan $\mathrm{t}$ hitung $=2,64$ Sedangkan $\mathrm{t}$ tabel $(\alpha=0,05 ; \mathrm{db}$ residual $=28$ ) adalah sebesar 2,048. Karena $\mathrm{t}$ hitung $>\mathrm{t}$ tabel yaitu 2,64 > 2,048 maka pengaruh pelayanan $\left(\mathrm{X}_{1}\right)$ adalah signifikan pada tingkat kesalahan $\alpha=5 \%$. Hal ini berarti $\mathrm{H}_{0}$ ditolak dan $\mathrm{H}_{1}$ diterima, sehingga dapat disimpulkan bahwa kinerja ekowisata dapat dipengaruhi secara signifikan oleh pelayanan.

- $t$ test antara hiburan $\left(\mathrm{X}_{2}\right)$ dengan kinerja ekowisata menunjukkan $\mathrm{t}$ hitung $=0,606$ Sedangkan $\mathrm{t}$ tabel $(\alpha=0,05 ; \mathrm{db}$ residual $=28$ ) adalah sebesar 2,048. Karena $\mathrm{t}$ hitung $<\mathrm{t}$ tabel yaitu $0,606<2,048$ maka pengaruh hiburan $\left(\mathrm{X}_{2}\right)$ adalah tidak signifikan pada tingkat kesalahan $\alpha=5 \%$. Sehingga dapat disimpulkan bahwa kinerja ekowisata tidak dapat dipengaruhi 
secara signifikan oleh hiburan pada $\alpha=5 \%$.

- $t$ test antara sarana pendukung $\left(\mathrm{X}_{3}\right)$ dengan kinerja ekowisata (Y) menunjukkan $\mathrm{t}$ hitung $=0,671$ Sedangkan t tabel $(\alpha=0,05 ; \mathrm{db}$ residual $=28$ ) adalah sebesar 2,048. Karena $\mathrm{t}$ hitung $<\mathrm{t}$ tabel yaitu $0,671<2,048$ maka pengaruh sarana pendukung $\left(\mathrm{X}_{3}\right)$ adalah tidak signifikan pada tingkat kesalahan $\alpha=5 \%$. Sehingga dapat disimpulkan bahwa kinerja ekowisata tidak dapat dipengaruhi secara signifikan oleh sarana pendukung pada $\alpha=5 \%$.

- $\mathrm{t}$ test antara kondisi alam $\left(\mathrm{X}_{4}\right)$ dengan kinerja ekowisata (Y) menunjukkan $\mathrm{t}$ hitung $=1,452$ Sedangkan t tabel $(\alpha=0,20 ; \mathrm{db}$ residual $=24)$ adalah sebesar 1,313. Karena $\mathrm{t}$ hitung $>\mathrm{t}$ tabel yaitu $1,452>1,313$ maka pengaruh kondisi alam $\left(\mathrm{X}_{4}\right)$ adalah signifikan pada tingkat kesalahan $\alpha=20 \%$. Sehingga dapat disimpulkan bahwa kinerja ekowisata dapat dipengaruhi secara signifikan oleh kondisi alam pada $\alpha=20 \%$.

\section{Pengujian Validitas Model}

Pengujian validitas model dapat dilihat dari nilai koefisien determinasi, Koefisien determinasi digunakan untuk melihat kontribusi variabel bebas terhadap variabel terikat. Koefisien determinasi $\left(\mathrm{R}^{2}\right)$ maupun koefisien determinasi yang disesuaikan menunjukkan variabel penjelas dalam menjelaskan variasi variabel terikat. Jika nilai $\mathrm{R}^{2}$ semakin mendekati 1 maka dapat dinyatakan model semakin baik dengan asumsi tidak terjadi regresi lancung. Berdasarkan analisa perhitungan diperoleh nilai $\mathrm{R}^{2}$ (R-squared) sebesar 0,4040 Artinya bahwa 40,40 $\%$ variabel kinerja ekowisata akan dijelaskan oleh variabel bebasnya, yaitu pelayanan, hiburan, sarana pendukung dan kondisi alam. Sedangkan sisanya sebesar $59,6 \%$ variabel kinerja ekowisata akan dijelaskan oleh variabel-variabel yang lain yang tidak dibahas dalam penelitian ini.

Agar mengetahui variabel yang mempunyai pengaruh paling dominan terhadap kinerja ekowisata dapat dilihat dari nilai probabilitas. Variabel bebas memiliki nilai probabilitas yang terendah 
menunjukkan bahwa variabel tersebut merupakan variabel yang memiliki pengaruh paling dominan terhadap variabel terikat.

Berdasarkan hasil analisis, maka dengan membandingkan nilai probabilitas dari masing-masing variabel dapat diambil kesimpulan bahwa variabel yang mempunyai pengaruh paling dominan terhadap besarnya kinerja ekowisata adalah pelayanan. Sedangkan probabilitas terendah kedua, ketiga dan keempat yaitu kondisi alam, hiburan dan sarana pendukung.

Pengaruh hiburan dan sarana pendukung yang tidak signifikan menunjukkan bahwa kedua variabel tersebut bukanlah menjadi penentu utama kepuasan pengunjung sebagai representasi dari kinerja ekowisata. Pelayanan dan kondisi alam yang menjadi penentu utama kepuasan pengunjung, hal inilah yang berpengaruh secara signifikan terhadap kinerja ekowisata di Kabupaten Malang. Hal ini sesuai dengan Pergeseran konsep kepariwisataan dunia kepada pariwisata minat khusus atau yang dikenal dengan Ekowisata, dimana saat ini ada kecenderungan semakin banyak wisatawan yang mengunjungi objek berbasis alam dan budaya penduduk lokal. (Fandeli, 2002)

\section{PENUTUP}

Berdasarkan hasil analisis dapat diperoleh kesimpulan sebagai berikut: pertama, Pengaruh hiburan dan sarana pendukung yang tidak signifikan menunjukkan bahwa kedua variabel tersebut bukanlah menjadi penentu utama kepuasan pengunjung sebagai representasi dari kinerja ekowisata. Akan tetapi, pelayanan dan kondisi alam yang lebih berpengaruh secara signifikan terhadap kinerja ekowisata di Kabupaten Malang.

Kedua, Keberhasilan ekowisata sangat ditentukan dari manajemen pengelolaan sebagaimana hasil analisis yang menunjukkan pelayanan merupakan variabel yang dominan dalam mempengaruhi kepuasan pengunjung, sehingga hal ini membutuhkan sinergi dari semua pihak termasuk juga kebijakan pemerintah.

\section{DAFTAR PUSTAKA}

Chafid Fandeli, 2002. Dasar-dasar Manajemen Kepariwisataan Alam, Yogyakarta: Liberti. 
Connel, Joan at al., 1979. Migration From Rural Areas, The Evidance from Villages Studies, Delhi: Oxford University Press.

Boedirachminarni, Arfida dan Suliswanto, M.S.W. 2015. Strategi Pengembangan Bisnis Ekowisata Kabupaten Malang. Proceeding ICEBM $2016 . \quad$ Universitas Tarumanagara.

Damanik, Janianton dan Helmut F. Weber. 2006. Perencanaan Ekowisata: Dari Teori ke Aplikasi. PUSPAR UGM dan Penerbit Andi. Yogyakarta.

David, F.R. 2004. Manajemen Strategis : Konsep. Edisi ketujuh. PT. Prenhallindo, Jakarta.

Hadinoto, 1997. Perencanaan Pengembangan Destinasi Pariwisata, Jakarta: PT. Gramedia.

Hagues Paul dan Haris, 1985. Sampling dan Statistik (Penterjemah Yulianto), Jakarta: LPPM dan PT Pustaka Binaman Pressindo.

Hari Karyono, 1997. Kepariwisataan, Jakarta: Penerbit PT. Gramedia Widisauna Indonesia.

Kusmayadi, Sugiarto E, 2000. Metodologi Penelitian Dalam Bidang Kepariwisataan, Jakarta: PT Gramedia Pustaka Utama.

Liem Bik Gwat, J. G., 1997. Bertandang Memandang
Kehidupan dan Kematian Dalam Kepariwis-taan Toraja (Kajian tentang Kahidupan Masyarakat Toraja Menghadapi Pariwisata Budaya di Tanah Toraja, Salatiga: Tesis UKSW

Marpaung Happy, 2000. Pengetahuan Kepariwistaan, Bandung: Alfabeta.

Mchintos, Robert W and Charles R Goeldner, 1990. Tourism: Principles, Practice, Philosophies, New York: Jogn Wiley and Sons Inc.

Mira P. Gunawan, 1999. Pariwisata Indonesia, Berbagai Aspek dan Gagasan Pembangunan, Bandung: Penerbit Lembaga Penelitian ITB.

Moeljarto Tjokrowinoto.2002. Pembangunan Dilema dan Tantangan, Yogyakarta: Pustaka Pelajar.

Moleong, Lexy J. 2005. Metodologi Penelitian Kualitatif. PT Remaja Rosdakarya. Bandung.

Soekadijo, R.G, 1996. Memahami Pariwisata Sebagai Sistemic Linkage, Jakarta: Penerbit PT Gramedia Pustaka.

Spillane James J., 1998. Ekonomi Pariwisata, Sejarah dan Prospeknya, Yogyakarta: Penerbit Kanisius.

Sugandhy Aca, 1993. "Pembangunan Pariwisata Berwawasan Lingkungan ", Makalah Seminar, Halaman 10-11, Jakarta. 
Analisis Kepuasan Pengunjung Ekowisata .....(Arfida, Suliswanto)

Umar Husein. 2008. Evaluasi Kinerja Perusahaan. PT. Gramedia Pustaka Utama Jakarta.

Menteri Dalam Negeri Republik Indonesia. 2009. Peraturan Menteri Dalam Negeri Nomor 22 Tahun 2009 Tentang Pedoman Pengembangan Ekowisata di Daerah. Jakarta: Departemen Dalam Negeri.

Prajogo, Uke. 2010. Model Kewirausahaan Berbasis Ekowisata Sebagai Upaya Pengentasan Kemiskinan Bagi Masyarakat Pinggir Hutan di Wilayah Rawan Illegal Logging. Makalah disajikan dalam rangka Dies Natalis XXXIX, Wisuda Sarjana (SI) dan Pascasarjana (S2) semester gasal 2009/2010 STIE Malangkucecwara Malang.

Yakin, Addinul. 1997. Ekonomi Sumberdaya dan Lingkungan. Jakarta: Akademika Prestindo.

Zubaedi. 2007. Wacana Pembangunan Alternatif: Ragam Perpektif Pengembangan dan Pemberdayaan Masyarakat. Jogjakarta:Ar-Ruzz Media. 